\title{
Intercultural Communication, the Influence of Trauma, and the Pursuit of Asylum in the United States
}

\author{
Sarah C. Bishop ${ }^{1}$ \\ Baruch College, City University of New York, USA
}

\begin{abstract}
This project analyzes the roles of communication and culture in credible fear interviews and asylum hearings in the United States to elucidate how autobiographical testimonies enable and restrain asylum seekers in their efforts to establish themselves as deserving of protection. This work shows how trauma influences one's ability to narrate their past and argues that culturally-bound storytelling norms negatively and unevenly threaten the outcomes of some asylum cases. I support this claim with evidence from oral history interviews with asylum seekers, immigration officers, judges, and attorneys.
\end{abstract}

Keywords: evidence, forced migration, intercultural communication, narrative, trauma.

\section{The U.S. Asylum Process and its Perils}

Each year, tens of thousands of individuals arrive in the United States seeking protection from persecution. According to the U.S. Department of Homeland Security (DHS), of the 264,945 people who sought asylum in the U.S. in fiscal year 2018 (the most recent year for which data is available), 38,687 were granted asylum - a rate of less than 15\% (Mossad, 2019).

For those who brave the odds, there are two paths to asylum in the U.S.: affirmative and defensive asylum processing. In affirmative cases, an individual physically present in the U.S. files for asylum by submitting form I-589, Application for Asylum and for Withholding of Removal, to U.S. Citizenship and Immigration Services (USCIS). The applicant then appears in a scheduled interview-officially "non-adversarial"-with a USCIS asylum officer. The asylum seeker is allowed to bring an attorney to that interview, in addition to necessary witnesses; if the applicant cannot complete the interview in English, it is their responsibility to provide their own interpreter. An asylum officer may make one of three decisions: grant of asylum, referral to an immigration court, or denial. If the asylum officer determines that an applicant is not eligible for asylum, the applicant is issued a notice to appear for defensive asylum processing. If the asylum officer refers the case to immigration court for further review, the asylum seeker is issued form I-862, Notice to Appear before an immigration judge (U.S. Citizenship and Immigration Services [USCIS], 2015).

In defensive asylum processing, an individual already in removal proceedings with the Executive Office for Immigration Review (EOIR) — whether because their affirmative asylum application has been denied, they have been detained within the U.S. due to their undocumented status, or they have been apprehended by U.S. Customs and Border Protection (CBP) trying to cross the border without documents and referred to defensive asylum processing following a credible fear interview with an asylum officer-requests asylum as a defense against removal from the U.S. These proceedings are adversarial, taking place in a hearing in front of an immigration judge. Although the court is tasked with providing interpreters for these hearings and immigration courts are legally required to provide applicants with a list of local free or low-cost legal services,

${ }^{1}$ Corresponding Author E-Mail: sarahcbishop@ gmail.com 
the government will not shoulder the cost of representation; again, applicants must provide their own attorneys or go without (Ardalan, 2015, p. 1006; USCIS, 2020). Many applicants navigate the process without counsel - a prospect more than twice as likely for detained applicants as for nondetained-despite the fact that in every asylum hearing a government attorney is present to represent the interests of U.S. Immigration and Customs Enforcement (ICE) (Ardalan, 2015).

Although in broad strokes the process may seem straightforward, pitfalls abound. Immigration attorneys are highly skilled at assisting asylum seekers in the process of writing and telling their immigration stories, and applicants with access to legal counsel are more than twice as likely as those without counsel to have their cases approved (American Immigration Council, 2016). Unfortunately, fraudulent legal advice runs rampant, especially in big cities like New York, where "travel agencies" and "notarios" sell and submit fake asylum narratives on behalf of uninformed migrants that often lead to the detainment and deportation of individuals with credible histories of persecution (American Bar Association, 2018).

Further complicating the process, the current U.S. political climate normalizes the criminalization and separation of families who have been forced to flee their homes due to horrific persecution. Former president Donald Trump called the asylum system "a big fat con job" and suggested that the migrants arriving at the U.S.'s border with Mexico in need of protection are fraudulent and dangerous gangsters who threaten the lives of Americans (Phifer, 2019). The Trump administration's immigration policy focused on changing the country's asylum policies and steadily and dramatically lowering quotas on refugee admissions, reducing the quota to 15,000 people in fiscal year 2021, a drop of over $80 \%$ compared to the year Trump took office (Watson \& Lee, 2020). At the same time, USCIS and DHS data show that ICE arrests within the US - as distinct from CBP arrests, which take place at the border-have dropped from a high of 297,898 in 2009, the first year of Barack Obama's presidency, to 143,099 in 2019, and that the Obama-era high of 432,281 deportations of undocumented immigrants had fallen to 337,287 in 2018 (Gramlich, 2020).

\section{Approaching the Asylum Process from an Intercultural Communication Perspective}

Missing from this administrative and political outline of the U.S. asylum process is the narrative burden placed on the asylum seeker. In navigating the legal asylum process, both affirmative and defensive applicants must recount multiple times, in writing and orally, the experiences that forced them to flee their homes. Applicants present their narratives on paper as part of the I-589 Application for Asylum, and then must tell parts of this story out loud when requested by an asylum officer who conducts the interview that marks the beginning of the legal asylum process. When officers refer applicants to an official asylum hearing before a judge, both the written and verbal narrative appear again. The stakes are high, and the grave danger asylum seekers face after being denied and deported is well-documented: the Columbia University Global Migration Project keeps a growing database with over sixty entries of people who were murdered or faced other direct harms after being deported; a report from Human Rights Watch (2020) offers evidence of 138 Salvadorans who have been killed since 2013 after being deported from the United States.

Asylee status enables an applicant to apply for legal permanent residence after one year (USCIS, 2015). But the majority will be denied. Considering that the majority of asylum seekers face being returned to the very circumstances from which they fled (Mossad, 2019), much hinges on asylum seekers' ability to effectively narrate their pasts to immigration officials during the asylum process. This project concentrates specifically on the oral testimony given during asylum interviews and hearings rather than the written testimony that accompanies the I-589. Because of 
its more ephemeral nature and the methodological hurdles associated with access, oral testimony has received less attention than written testimony in asylum research. ${ }^{2}$

In the government's quest to determine an applicant's credibility from their oral narrative, little is out of bounds. Asylum officers and immigration judges regularly ask applicants to produce physical evidence of bodily harm, describe the graphic details of violent sexual encounters and torture, and account for any and all delays in their decisions to flee their homes. ${ }^{3}$ Having a viable story is not enough, and nor is the ability to write it down—one must also be able to tell it.

In this context, mitigating the potential for misunderstanding in a setting marked by trauma and intercultural communication takes on a new and menacing urgency. I define intercultural communication as any verbal or nonverbal interaction between two or more parties from different cultural backgrounds. Asylum cases are inherently contexts of intercultural communication as they invariably involve the interaction of a foreign national with a U.S.-resident officer or judge.

\section{Review of the Literature}

Differences in cultural norms may have an outsized effect on the outcome of a case if applicants, officers, and judges are not aware of and adept at negotiating these differences. This difficulty is long-recognized. In a seminal study about the Swiss asylum process, Kälin (1986) explored five obstacles - manner of expression, the influence of interpreters, culturally-bound concepts, differences in the perception of time, and cultural differences in expectations surrounding the ideas of "truth" and "lies" - that can distort communication during asylum hearings and endanger an asylum seeker's application. In Kälin's account, especially in cases without extensive written evidence, in-person communication between the asylum seeker and the asylum officer or immigration judge is crucial.

Other communication-centric international research has likewise addressed the challenges that narrative and cultural differences present in the asylum process, such as Smith-Khan's (2017) critique of the policy documents Australian officials use to attempt to standardize asylum narratives, which reveals that cultural and individual characteristics of asylum seekers makes variation inevitable. In subsequent work, Smith-Khan (2018) argues that potential refugees arriving in Australia are held responsible for "performing credibility" but are at a disadvantage from the start as they must do so within a discourse that is not their own - and often presumes their dishonesty (p. 6) - and illuminates the ways varying amounts of communicative skill and differing narrative choices made by asylum seekers' attorneys affect case outcomes both positively and negatively (Smith-Khan, 2020). Blommaert's (2001) work shows a contrast between the greater amount of narrative context African asylum seekers attempt to include in their application narratives and the lesser amount of context the Belgium procedure is designed to permit. McFadyen (2019) demonstrates how asylum seekers in the UK may use silence as a means of nonverbally claiming some agency during their asylum interviews; Wernesjö (2019) likewise emphasizes asylum seekers' communicative agency by showing how unaccompanied minors arriving in Sweden use narratives of responsibility and education to frame themselves as aspirational young people deserving of protection. In an ethnographic study of several European states, Jacquemet (2015) showed asylum officers' heavy and culturally-rooted reliance on specific communicative details to determine credibility, such as asylum seekers' use of proper names in their

\footnotetext{
${ }^{2}$ Oral and written testimony may work in tandem in cases where credible fear interviews are transcribed and then the transcription used by judges during the hearing of oral testimony on order to check for consistency and discrepancy.

${ }^{3}$ For a more comprehensive overview of the stages of legal asylum process in the U.S., see the American Immigration Council's “Asylum in the United States" (2018).
} 
autobiographical accounts. Likewise, Gibb and Good (2014) demonstrate how the need for and presence of an interpreter may alter the substance of asylum hearings in the United Kingdom and France. These useful existing international studies notwithstanding, asylum seekers are regularly underrepresented in academic research, in part because they are too often conflated with refugeeswho receive approval for governmental protection before their arrival in their country of resettlement-rather than regarded as a distinct group that faces the unique communicative challenges of the post-arrival legal asylum process.

Although forced migration scholarship has primarily been the purview of scholars of political science or international relations, communication studies' close attention to intercultural differences in interactions, nonverbal communication, and the construction of the self though narrative signifies that this perspective has much to add. Without a communication perspective, one risks making an implicit assumption that the outcome of an asylum case depends only on whether the applicant has a credible history of persecution. Communication theorist Walter Fisher (1989) advanced a narrative paradigm to investigate how individuals use storytelling tools in a wide array of interactive contexts as they send and receive messages, acting as co-authors of a narrative as they evaluate each other's messages. Fisher asserted that " $\mathrm{t}] \mathrm{o}$ apply a narrative paradigm to communication is to hold, along with Aristotle, that people have a natural tendency to prefer what they perceive as the true and the just" (p. 65). The relevance of his paradigm to the asylum context becomes clear when one considers that an asylum officer or judge's preference for "what they perceive as the true and the just"-say, for the presence of proper nouns in an asylee's testimony - has serious, direct implications for an applicant's safety and immigration status.

USCIS officers are trained to listen for any inconsistencies or irregularities in applicants' narratives that suggest fabrication. The applicants' slightest verbal or nonverbal missteps - whether the result of embellishment, nerves, or just the fallibility of memory - can disqualify their case. Scholars and immigrant rights activists have documented the "pervasive climate of disbelief" that engulfs the asylum-seeking process (Shuman \& Bohmer, 2004, p. 406; see also Bhabha \& Smith, 2007; Dolnick, 2011; Fobear, 2015; Gurer, 2019). Bond and Atoum (2000) found evidence of "cross-cultural similarities in the way that liars act and that behavioral concomitants of deception can be identified across cultures" (p. 394); still, listeners were more likely to judge speakers as deceptive if they were speaking in an unfamiliar language rather than the listener's language. These findings make clear why communication makes up the core of the asylum-seeking process, operating, as McFadyen (2019) writes, as "both a key, and a barrier, to refuge" (p. 168). Only by foregrounding a communication perspective can one comprehend how the power and pitfalls of narrative may assist or threaten an asylum seeker in the quest for protection.

\section{Research Questions}

Because the outcome of the asylum process "depends almost entirely on the story of the claimant" (Wooley, 2017, p. 378), more work is necessary that (1) interrogates the power and limitations of narrative in the legal asylum process, (2) explores from a communication-centric perspective the intercultural transfer of culturally-bound storytelling conventions it entails, and (3) foregrounds the voices of asylum seekers themselves, providing a look behind the closed doors of the legal process. Guided by these goals, my project sets out to address the following research questions:

1. What does centering the perspectives of asylum seekers reveal about the specific, culturally-bound narrative conventions required by the legal U.S. asylum application process? 
2. How does an applicant's in/adherence to these communicative and cultural norms affect asylum seekers' experiences and outcomes?

Drawing from in-depth interviews with asylum applicants, immigration attorneys, former immigration officers, judges, and doctors who conduct psychological evaluations of asylum seekers, this study challenges the prevailing opacity of the asylum-seeking process and shows how culturally-bound communicative norms negatively and unevenly affect some asylum applicants.

\section{Methodology}

There are many players in the drama of asylum. From 2018 to 2020 I conducted twentyseven oral history interviews in New York City: thirteen interviews with asylum seekers and asylees from Central and South America, Africa, and Asia, three with immigration judges, three with asylum officers, two with doctors who provide psychological evaluations of asylum seekers to be used in their legal cases, and six with attorneys. I recruited participants by leveraging my affiliation with local immigrant-rights serving organizations and through snowball sampling.

Oral history involves in-depth autobiographical interviews with questions that are designed to not anticipate particular findings. I prepared an interview guide with questions that varied according to the role interviewees play in the asylum process. I attempted to avoid the pervasive underpayment of immigrant labor by offering cash incentives to each asylum seeker who participated; the officers, judges, and attorneys donated their time. Federal regulation 45 CFR 46.102(1) excludes oral history research from Institutional Review Board review because the method does not seek to produce general knowledge claims from a representative sample of participants. In lieu of the protections the IRB would provide, my project follows the best practices of the Oral History Association, the governing body for this method. All interviewees provided written consent via a deed of gift which was provided and discussed before each interview and signed by both interviewer and interviewee post interview. All participants received the opportunity to restrict parts of their interview from being included in the research project. The interviews were conducted in English, with paid interpreters for participants who chose to participate in Spanish and Bambara.

In adherence with practices of trauma-informed interviewing, I did not ask the asylumseeking participants about why they had to flee their homes. As interviews have the potential to retraumatize interviewees who have undergone traumatic stress, this choice shielded those who only wanted to share about life after their arrival in the U.S. (Langballe \& Schultz, 2017; SAMHSA, 2014). Even so, the nature of oral history interviews is such that interviewees have a good deal of opportunity to steer the conversation themselves. Several of the narrators chose to tell me about why they left home despite not being asked, and in the work that follows I aim to carefully and ethically present what resulted from those conversations. In secure contexts, telling one's story has the capacity to catalyze healing and regain agency over one's experiences (Coundouriotis, 2006; Hacket \& Rolston, 2009; Sharf \& Vanderford, 2003). Notably, studies show that selfexploration, especially in light of tragic experiences, can provide new insight and opportunities to recognize positive personal growth (McAdams, 2001; Stuhlmiller, 2001). To protect asylum seeking narrators' identities, I asked them to choose pseudonyms, and we talked after each interview about whether there were any parts of the interview that they wanted to restrict from the project. I have excluded from this article identifying information of these participants' places of work, ages, and, in some cases, their current immigration status. 
I audio recorded each interview and had them professionally transcribed. A deep reading of the transcribed data revealed some thematic commonalities across interviews as well as experiences that were specific to particular individuals and not shared by other participants. A research assistant inserted the interview data into a spreadsheet workbook, taking care to maintain the narrative integrity of the data while coding excerpts of the interviews into their corresponding themes, such as "difficulty remembering the past," "normalizing persecution," and "emotions during court hearings." Rather than separating the asylum applicants' interview data from the reflections of the governmental/legal personnel, we placed them into a single spreadsheet in order to achieve the goal of considering these perspectives side-by-side to see how they compared to and illuminated one another. The perspectives that are included in what follows are a narrow sampling of findings that appeared recurrently across interviews, chosen for coherence around the ideas of narrative, communication, and culture.

\section{Findings and Discussion}

Both immigration personnel and asylum seekers exist in several overlapping cultures at once; intersecting and dynamic attributes such as age, religion, political beliefs, socioeconomic status, and geographic location influence one's sense of what is or is not normal, and may affect the style in which one communicates. Acknowledging the effect of culture on behavior and the interpretation of behavior in the asylum process, USCIS's Asylum Officer Training curriculum includes a module titled "Cross-Cultural Communication and Other Factors That May Impede Communication at an Interview" (USCIS, 2019a, p. 6). The materials contain several communication-centric directions for officers, including "Focus on the interviewee and listen to what he or she is saying," (USCIS, 2019a, pp. 20) and "be aware of the potential for miscommunication when a second language is used" (USCIS, 2019a, pp. 9). Much of the content is cursory; the section on eye contact for example, is comprised of only two sentences: "Eye contact varies from culture to culture. What may be considered a normal length of time for eye contact in one culture, may, in another culture, be termed 'staring' and considered rude, causing the other person to feel uncomfortable" (USCIS, 2019a, p. 9). No mention of to which cultures this applies or of the impact of trauma on eye contact is included.

The narrators who participated in this project revealed the asylum process as a nexus of dissimilar communication styles rooted in disparate cultural norms that manifest in ways that prove problematic for applicants. Specifically, these differences in communication styles threaten to make applicants seem less credible, thereby jeopardizing their ability to prove a "well-founded fear of persecution." As the officers and judges I interviewed made perfectly clear, this is a common and key obstacle in the legal asylum process. Judge Charles Honeyman told me that over the course of his career he heard testimony from "some truthful [applicants that] were so ineffective and stumbling as to be unbelievable," while in other cases there was "the potential for some proportion of people who have fraudulent or exaggerated claims to get through and get granted asylum and all the benefits because they're going to tell a story well - What I'm saying is that there is not a perfect science." Likewise, former officer Martha Parmalee explained, "There have been cases where I thought, this person has a real case, but they're just afraid. They won't tell me. No matter what I did, I couldn't get it out of them. Those really bothered me, those cases." As these reflections reveal, applicants' chances of success very much depend on their communicative ability, necessitating a closer look at this underexamined facet of the asylum process.

Here, I have divided the intercultural communication hurdles of asylum into three related but distinct themes - the challenges of fitting the story of a chaotic life experience into the narrow strictures demanded by an asylum interview or hearing; the obstacles that cultural differences in 
autobiographical recollection and the effects of trauma on memory present for the construction of a coherent narrative of persecution; and the difficulty asylum seekers may have presenting normalized trauma and abuse as extraordinary in using it as the basis for a claim of credible fearto consider both how they operate individually and the ways they intertwine and affect one other.

Each of these three themes is regularly influenced by trauma. Because trauma is so pervasive in the asylum process, I attempt to show how it colors all of the findings rather than compartmentalizing it into a section of its own. In what follows, I rely heavily on the expert insights of psychologists who regularly work with asylum seekers as well as existing research on trauma in contexts of the memory of forced migration. I build on this integral work in psychology by placing it in conversation with communication-centric inquiry about narrative. With this approach, I aim to advance an interdisciplinary dialogue that emphasizes not just how trauma affects how asylum seekers remember their pasts, but also the impact of the cultural clash that occurs when individuals must perform these memories through communicative behaviors in compulsory contexts.

\section{From Chaos to Order: Fitting Unwieldy Experience into Narrow Legal Parameters}

A.B. was born in Nigeria and had to flee when others' knowledge of his sexual orientation began to threaten his life. Entering his asylum interview expecting to be able to share at length about the hardships this experience had caused him, A.B. was flummoxed when the officer interviewing him seemed to grow frustrated by the amount of detail he was providing. "He just wanted 'yes' or 'no' kind of answers, so, I guess I was overdoing it, maybe that was the problem," A.B. told me. "I was trying to buttress my points, making him understand more. Maybe that was what pissed him off. I don't know. He was [saying], 'No, I just want this, I just want this!' I [replied], 'Yes, I understand, but I'm trying to - if you ask me an open-ended question, you don't just expect me to just say yes or no, I have to be able to explain to you.'" The differences between the asylum officer's style of communication and A.B.'s created what A.B. perceived as "a friction in the course of the interview."

A.B. knew enough about asylum law to understand that while immigration officers cannot grant arriving asylum seekers' cases - a task reserved only for immigration judges - they can deny applicants, after which the choice is one between a difficult appeals process or deportation. A feeling of frantic desperation accompanied his narrative as he realized, "if I'm not able to pass this stage, then, that's the end." The fact that his interview felt rushed only flustered him further. "The way [the officer] was [verbally] hitting back at me, says probably I'm taking too much of his time. I guess he has other guys to attend to." A.B. left his interview disappointed that he had not been allowed to share the complexity of his experiences and scared to learn the result.

During the credible fear interview that determines whether one's case will be heard before a judge, USCIS instructs applicants to "[t]ell the Asylum Officer your experiences in as much detail as possible so that the Asylum Officer can determine whether you qualify as a refugee" (USCIS, 2012, emphasis added). The ability to relay sufficient detail is paramount, but not all details are welcome in this story. USCIS has no use for memories that do not involve the five particular classes of persecution detailed in the 1951 Refugee Convention: "race, religion, nationality, membership in a particular social group, or political opinion." This definition of a refugee delimits who is eligible to receive consideration for asylum status. The entirety of the process is designed to see if an individual meets this definition. As the narrators in this section reveal, wrangling the complex and chaotic details of their lives into such narrow narrative parameters presents a communicative challenge that sometimes proves insurmountable.

Much of the difficulty of narrating one's experiences of persecution in a way that aligns 
with the legal parameters of asylum system stems from the reality that many individuals who arrive in the U.S. in need of protection have no existing understanding of asylum or the five grounds on which to prove one's need for it (see Bohmer \& Shuman, 2007; Haas, 2017). Still, the narrators in this project emphasize that knowledge of the conventions does not guarantee success. Elizabeta Markuci, an attorney at a nonprofit organization that offers pro bono immigration services, explained that even when applicants understand what the legal standards are, the nuances of the law are so complex that it's unlikely their stories will just "naturally" fit the parameters. "It took me a while in law school [to learn] those concepts, right? So how do you distill that for someone?" she wonders. "There's the statute, the law that you have to prove, but how do you interpret the law?" Successful interpretation requires applicants to organize the chaotic events preceding their forced migration into a linear narrative that offers an unobstructed understanding of who caused an individual's persecution and why.

USCIS's (2015) Asylum Officer Training Materials address this problem explicitly in a section called "The Interviewee May Not Know What Is Important to Disclose." It reads, "The interviewee is not likely to be familiar with U.S. immigration laws and regulations and what is necessary to establish eligibility...he or she will not be familiar with the interview process. You [the officer in training], however, are the authority on relevant law, what is necessary to establish eligibility, and the interview process" (p. 13). This section rhetorically removes the relevance of asylum seekers as experts in their own life experiences - the experiences that establish eligibility under the 1951 Refugee Convention - and endows the officer alone with the power to know and extract what is relevant from the interview.

Martha Parmalee, a former asylum officer who spent years listening to immigrants' testimonies, believes that "the most difficult" task confronting asylum seekers is to fit their confusing and chaotic histories into the tidy parameters required by the five grounds of the Refugee Convention. "If it's not clearly political opinion or race, religion," Martha shared, it proves especially difficult to "try and figure out what kind of "particular social group' you might fit into." This difficulty is compounded, as both Jacquemet (2013) and Spotti (2018) describe, by the fact that the asylum process is a trans-idiomatic environment in applicant and official may use incompatible words to name the same things or experiences even when both parties speak the same language. This incongruence can be amplified when an interpreter is required (Gibb \& Good, 2014; Kälin, 1986; Maryns, 2013).

One of the variables that the attorneys I interviewed encounter often is the difficulty of knowing and being able to prove a story's "villain," responsible for the persecution that an asylum seeker faced or fears they will face in the future. Elizabeta explained,

One of the jokes that people repeat in the practice of immigration law is like, no persecutor is going to give you a note [that says,] "I tortured you because you are part of this political party or because of your race or because of your religion." So showing that connection is sometimes really challenging and that's why you submit so much documentation to make those puzzle links that you're not just someone who's at the wrong place at the wrong time.

The ability to clearly point to a persecutor is imperative for establishing a clear villain against whom the protagonist-cum-applicant can attempt to prevail. In this context, documentary proof is often called upon to substantiate oral explanations. Former immigration judge Sue Roy explained, "For instance, maybe you can't prove that 'Joe the MS-13 member' was targeting you specifically, because you don't really know who he was, right? But you know that he was extorting 
you for money." In this case, Judge Roy would tell an applicant, "get your bank records that show that you were taking out [funds] every month. Those kinds of things can still help support your claim and shouldn't be that hard for people to get." In Judge Roy's hypothetical scenario, documentary records support narrative arguments to the benefit of the applicant. But her suggestions that these records "shouldn't be that hard for people to get" does not fully account for contexts where systems that in theory exist to protect citizens sometimes work against them. For example, Mary told me she went through "a lot of problems to get the police report" in Nigeria that would offer evidence of the physical harm she suffered at the hands of her husband. "They said they don't want to give it because they needed money, they needed bribe before they could give out a report...the system is corrupt. If it's not corrupt, nobody would want to leave in the first place." The problem is not simply a lack of records, A.B. clarified; visiting the police station is dangerous. He told me people pray that they will never need to go.

These circumstances put some asylum seekers at a disadvantage since cases with documentary evidence to support narrative testimony may be viewed as more credible than oral testimony. Without evidence, A.B. knew his claim would be less viable. "A police report...they believe that is like more presentable, compared to having a testimony." Feeling the pressure of having little other choice, and lacking confidence that his complicated narrative would be enough without documentation to corroborate it, A.B. acquired a forged document that stated he had been invited to participate in a conference in the U.S. He hoped to use the document just to pass U.S. Customs at JFK Airport, but the officers detained him; he would spend the next six months in jail before receiving pro bono representation that helped him to prepare a more accurate case that was ultimately successful.

These accounts illuminate some reasons why credible applicants for asylum may be unable to produce asylum narratives that would lead to a successful outcome. As the narrators have shown, even applicants with claims that should make them eligible for asylum may find that complication, confusion, or chaos in their experience prohibits them from communicating their story in accordance with the strict and uniformly applied boundaries of current immigration policy. That is, not only must applicants have faced persecution that was a direct result of their race, religion, nationality, membership in a particular social group, or political opinion, but they must prove that this is the case through oral testimony that is remarkably efficient and evidentiary, stylistically conforming to the boundaries of what officers and judges believe to be plausible, in a national context where judges' beliefs, expertise, and grant rates vary dramatically (TRAC Reports, 2020).

\section{Chronology, Coherence, and Memory}

In a January 2020 presentation to prospective asylum applicants titled "How to Write your Asylum Story," attorney Amir Rasoulpour told participants, "In reality, your story is complicated, not necessarily chronological or in order, and things are not black and white. [But] your asylum story is not your full story. It is a story that focuses on the elements of asylum and presents them chronologically and clearly" (Rasoulpour, 2020). Rasoulpour's instructions make visible the inevitably dichotomous nature of narrative in asylum proceedings - the requirement for highly selective but precisely chronological narrative. As we heard from A.B., an applicant cannot provide an unedited and comprehensive view of their experience to support their case, and must instead curate a distillation, strategically choosing to reveal and leave out some lived experiences, maintaining linear chronology and coherence even while omitting major segments of life not relevant to the asylum process. This requirement poses a communicative challenge to applicants. As the narrators in this section reveal, this challenge is exacerbated by culturally-bound ways of 
chronicling time, the impact of trauma on memory, and the uncertainty of understanding which details to communicate and which to exclude.

When Jeff Chase began providing legal representation to asylum seekers in the 1980s, most of his clients were from Afghanistan. "One of the most difficult parts of preparing their asylum applications was determining dates," Jeff wrote on the blog he keeps about immigration; "[n]ot only the dates relating to events critical to their claim (i.e. when they were arrested; when they fled), but even the most basic info: the dates of their birth" (Chase, 2017). Jeff's struggle resulted from the fact that the official identity cards issued by the Afghan government would record someone's birthday by stating, for example, "was approximately eight years old in 1982." Jeff's attempt to pin down an exact date, he explained, was "further complicated by the fact that Afghanistan uses a completely different calendar from the west." Since neither Jeff nor his clients could reasonably determine this date, Jeff started to record his Afghani clients' birthdays as January 1. "When I once attended a Master Calendar hearing on January 2, the INS trial attorney joked that I must have been extremely busy the previous day, celebrating all of my clients' birthdays," Jeff remembers.

The application's requirement of relevant dates does not account for cultural differences like the ones Jeff describes. The 12-page I-589 Application for Asylum provides applicants with 48 spaces to "provide specific dates" about "each event or action described," such as the dates of the persecution they faced, help they sought, and their arrival in the U.S. In October 2018, USCIS changed the language on its website to read that it would not accept any applications "if you leave any fields blank" (USCIS, 2019b). The following month, the American Immigration Lawyers Association reported that rejections "due to claimed incompleteness" of the I-589 form were growing becoming frequent (American Immigration Lawyers Association, 2019). The Guardian reported on several such examples, like one in which an application was refused because it did not include a passport expiration date; like many asylum seekers, this particular applicant did not have a passport and thus no expiration date to report (Davis, 2019). This kind of bureaucratic insistence on dates that some applicants are unable to provide threatens the chances of protection for some viable candidates. Their applications must be complete when submitted, but recording any date that is later found not to be exact carries the real danger of jeopardizing their case. Compounded by the idea that traumatized individuals may have an even more difficult time remembering dates than others, the static application leaves asylum seekers with few choices.

The potential impact of trauma, highly personalized, is an especially intractable problem in this aspect of the current asylum system. The varied and unpredictable effects of traumatic experience on autobiographical memory are well-documented, and may include memory disorganization that can lead to difficulty encoding and organizing a narrative and an emphasis on emotional rather than more tangible details in recounting an event (Bremner \& Marmar, 1998; Crespo \& Fernández-Lansac, 2016; Herlihy \& Turner, 2007). Hellawell and Brewin's (2004) salient work shows that memories of traumatic events may be available only as perceptual snapshots - flashes of partial but poignant sensory recollection - that are involuntarily triggered rather than remembered via the kind of voluntary recall that one must attempt during the asylum process. Graham et al. (2014) observed that asylum seekers' memories were "overgeneral," that is, less specific when compared to those of someone without post-traumatic stress symptoms. Trauma can also lead to memory distortion, affecting the accuracy of an individual's memory as both the effort of intentionally remembering the traumatic event - of the kind repeatedly required by the legal asylum process - and the incursion of unintentional, intrusive traumatic memories can lead people to "inadvertently generate additional imagery relating to those traces that fits with the experienced event," adding the content of memories of other events or even of media representations of similar events (Strange \& Takarangi, 2015). 
In March 2019, I arrived at Bellevue Hospital to meet Dr. Hawthorne "Hawk" Smith, the Director of the Program for Survivors of Torture (PSOT). PSOT is renowned for providing what Hawk calls a "resilience-based, strengths-based approach" to comprehensive mental health care for people who have been forcibly displaced from their homes and offering clients psychological evaluations that are regularly used as evidence in immigration court. The traumas PSOT's asylum seeking clients report having experienced are broad and bleak: around $70 \%$ have been physically beaten, $60 \%$ made to witness the murder or torture of others, $25 \%$ sexually assaulted or raped, $20 \%$ deprived of food and/or water, suspended in painful positions, or made to withstand mock executions and death threats (Bellevue/NYU PSOT, 2019).

Hawk explained to me how such experiences can affect a person's ability to accurately recall their past in a chronological fashion during the legal asylum process: "if we look at our brain as a library and our memories as books, under normal circumstances, the books are organized, codified, placed in a structured way, an organized way...but when someone is in a situation of extreme stress, extreme trauma...those books sort of get placed haphazardly — by the time someone is asked, 'So what happened on that day in September?' and they go to look for that book, the book is not there." Hawk's metaphor illustrates what trauma research has long reported: traumatic experiences inhibit individuals' abilities to recall and narrate with chronological specificity the details of their lives (see Graham et al., 2014; Johnsen \& Asbjørnsen, 2009; Samuelson, 2011).

Although asylum officers are trained to look for inconsistencies in applicants' testimony, Hawk points out that gaps in memory and "a little bit of inconsistency - it actually is not something that signals that the person... loses their credibility. In some ways, that is more consistent to someone who's actually been traumatized and trying to hold it together." In other words, traumatic experiences may cause the exact kind of lapses in memory and contradictions that signal dishonesty in other contexts, illuminating a crucial challenge for traumatized asylum applicants.

Aisha, who successfully petitioned for asylum after coming to the U.S. from Gambia, remembers from her legal experience just how unpredictable memory is. She told me, "Sometimes, you go through certain things, you are traumatized, you forget when they ask you. You can remember something but somebody else comes and starts asking you, you can forget. It happens because of trauma." The reality Aisha describes is further complicated by the unpredictability of the asylum process' duration. Whereas some recent asylum seekers have been rushed into credible fear interviews only hours after they arrive in the United States giving them too little time to prepare, others I spoke with have been made to wait years for their interview, during which time they must cling to painful memories so that they will be able to describe them in exacting detail when their time finally comes. Aisha emphasized that the ability to remember is not always consistent, and may fluctuate depending on the context: "Sometimes it happens...maybe if I talk to you today, you might not remember something but if I reach you, maybe, another time, you can remember." Existing work in the psychology of memory and its relation to trauma corroborates Aisha's experience (Giosan et al, 2009; Ratini, 2019; Wyshak, 2009). Unfortunately, because each asylum seeker receives just one credible fear interview, the asylum system cannot account for the variability of memory's accessibility in any given moment.

Amadeo, who fled Peru, was one of Hawk's clients at PSOT and remembers poignantly the difficulty of trying to remember and write down the details of the painful experiences he had worked to forget. The process took a toll. He told me, "Emotionally, I was a wreck back then, I guess. But the process itself was long. It wasn't easy. I think that the hardest part was...they asked me to write my story of how my life was back in Peru. It took me, like, a month to remember everything. Because I think back then, I [tried] to erase many memories, many bad memories that I had, and when I brought them back, I wasn't feeling well." PSOT worked with Amadeo to help 
him understand how to frame his story in a way that would most clearly align with the eligibility requirements for asylum. Amadeo's experiences of persecution were on account of his belonging to a particular social group - one of the five protected grounds - and the pain he experienced when reconstructing his memories in narrative form lifted when he was granted asylum and finally felt that he could leave his past behind.

Martha explained to me how applicants' uncertainty about which aspects of their experience to engage and avoid threatens their ability to construct a chronological narrative: "Part of the problem is, if people don't know what the requirements are, they're frightened. They know what they went through [but] they don't know what's important and what's not," Martha explained, sometimes causing the applicants to jump forward and backward in time as they narrate their lives. "Depending on their culture," Martha told me, asylum seekers may not realize that "I don't need your grandfather's history. I don't need to know what they're doing to your people. I need to know what they did to you, and who did it, and why." For applicants who see themselves less as individuals and more as members of a family and community group, explaining the full extent of their experience in a chronological fashion would require contextualization that the asylum process simply does not have the capacity to permit.

\section{Making the Familiar Strange: Dislocating Culturally-Bound Experience through Narrative}

Mary endured almost daily physical and sexual abuse from her husband in Nigeria. Recounting her experiences to me, she shrugged and explained, "I got married and I was told that the man has a higher hand. Whatever he says is final." Because of the cultural normalization of male dominance and abuse, Mary had a hard time finding support. Even the local police to whom on several occasions she reported her injuries, including broken bones, saw her struggle as a "family matter" and believed "[y]ou don't need to bother husband and wife." For years, she hid small amounts of money until she had finally saved enough to sneak to the airport with her children and fly to the United States. When she arrived, the immigration officer she encountered asked her why she hadn't left her husband earlier. 'I told him that I didn't know any better, I didn't know what to do. First of all, I didn't even know I was being molested. I didn't even know I was going through it back then. I thought it was a normal thing because of what we're told." Mary's story points to a serious challenge facing asylum applicants: local cultural norms may affect the ways applicants both understand and narrate their experiences in ways that threaten to have minor to significant negative impacts on the outcomes of their legal cases.

In some cases, human rights violations and other persecutorial practices become so normalized and naturalized that applicants may not mention them when they apply for asylum, even if these parts of their experience would be the most likely details to lead them to an approved case. For example, after the successful outcome of her own case, Aisha, who speaks six languages fluently, began working as an interpreter for asylum cases involving other African women, many of whom who have experienced female genital mutilation, or FGM. Aisha told me,

Depending on some stories, like the FGM, like you see [women] remorseful to bring it out, because some of them feel like the FGM sometimes, they preach that it's sacred, you don't have to tell other people about it, [especially] people that did not go through the process. So, sometimes people, they still have that [idea] in them, so they kind of hold back a little bit. 
While talking to a stranger about gruesome physical violence that one has encountered because of one's biological sex is a daunting hurtle on the way to protection, it is imperative to the asylum process that survivors of FGM overcome the belief in the practice's cultural "sacrality" and describe it instead as a form of torture. Existing research has shown that such internalization is common in cases of abuse, even when the abused party would not tolerate the same behavior directed toward a hypothetical other (Acevedo, 2008; Hlavka, 2014). As Aisha articulated succinctly, this is especially true of applicants whose persecution was longstanding: "Because this is what you survived all your life, you tend to even think it's normal."

When the persecution that individuals face begins to feel natural rather than unusual, it can take a good bit of work for an individual to defamiliarize what happened to them so that they can talk about it plainly. Amelia Wilson, a staff attorney at the Immigrants' Rights Clinic at Columbia University, told me she has encountered several cases of persecution that had come to seem so normal to her clients that it was difficult for her to convince them of the necessity of talking about these events during their asylum process. In one recent case, Amelia represented a young woman who was raped by her father at a young age and later physically and sexually abused by her husband. But when Amelia quizzed the client with some questions that were likely to be asked during her asylum hearing - "What's the worst thing that ever happened to you?" and "Have you ever suffered harm in the past?"- -her client did not even mention this abuse. Instead, she would answer by talking about the hardship that a miscarriage had caused her. "It was so heartbreaking," Amelia told me. "She would identify other things that weren't that she was beaten mercilessly by her husband on a daily basis, or that her father had raped her." Although Amelia did eventually convince her client of the necessity of communicating these realities during her hearing, it pains her to think about the many survivors who keep such experiences quiet. "I think a lot of the women who have suffered DV [domestic violence] at the hands of their husbands, they haven't seen it themselves as persecution," she shared. "It's so normalized in certain cultures that men would beat their wives...They've internalized their own subjugation."

The internalization of persecution is not limited to survivors of domestic violence, though it is perhaps most well documented in this population (Wood, 2001). Amelia has also represented several applicants who applied for asylum on the basis of persecution they experienced as a result of social attitudes toward their homosexuality. In one such current case, she explained, the client "talks about [their] own sexuality in a way that is shameful, [which] has acted adversely to their credibility because they use terminology that we don't use to talk about them, that makes it sound like they're even homophobic." Amelia remembers another client who always referred to himself as "a gay."

\section{He won't say, "I'm gay." He's like, "I'm a gay,” or say, "Well, I am a faggot." He'll use derogatory terminology, but not in an empowering way like he's reclaiming the word, but in a way like he's just a person who is not worthy of fair treatment. He'll justify things that have happened to him because of his sexual orientation.}

Having internalized prejudiced thoughts toward particular groups may lead asylum applicants to unintentionally undermine their own cases through the way they communicate about their identity.

This can present a particular problem for asylum applicants when their practices of secrecy or internalized homophobia mean that they present themselves in ways that aren't perceived by representatives of the government as legibly LGBT. Some applicants react to this pressure by 
behaving in artificial ways based on stereotypes of sexual minorities (Heller, 2009). In a process so contingent on determinations of credibility, this can be a dangerous strategy. Indeed, some asylum processes revolve less around whether an LGBT applicant might have a credible fear of persecution than whether or not they actually are part of a sexual minority; even if they are believed, applicants who do not read as obviously LGBT to the asylum officer or immigration judge may be encouraged to simply continue hiding their sexuality in their nation of origin to avoid persecution (Carillo, 2010; Millbank, 2010). Further, as Carrillo (2010) has shown, beginning in the early 1990s "[t]he need to legally establish the immutability of homosexuality" - to have it be recognized by U.S. immigration officials as a fixed characteristic rather than a practice that applicants could be expected to change in order to remain safely in their nations of origin - recommended the adoption of an essentialist, biological understanding of sexuality that further obscures any cultural influences over an LGBT applicant's actions and presentation (p. 446). These cases risk failing to draw sufficient attention to the ways individuals were persecuted on the basis of their membership in a particular social group. While a savvy attorney may be able to overcome this hurdle with clients by practicing with them ways of talking about their experiences of persecution, clients without representation may never get the chance.

Existing trauma research complicates explanations about why an asylum seeker may verbally downplay the harms they experienced by showing how memory changes over time in response to both the context in which one is asked to recall an event and the status of one's recovery from trauma. This work shows that rather than existing in individuals as static realities, "memories are continually reconstructed in accord with previous knowledge and experiences, attitudes, belief systems, and the conditions and context at the time of recall" (Dekel \& Bonanno, 2013, p. 27). Individuals experiencing symptoms of PTSD when they recount a memory tend to recall more trauma than when they are not experiencing symptoms (Engelhard et al., 2008). Likewise, individuals whose experience of trauma leads to worse mental health outcomes become more accurate narrators of a traumatic event over time, while individuals who recover more readily modify their original narratives to be more benign, matching their progressive recovery (Dekel \& Bonanno, 2013). It is clear how these cognitive realities may work against applicants within the U.S. asylum process and in international asylum processes - if an applicant's mental recovery from traumatic events is inversely correlated to their ability to describe the severity of the persecution they faced, their resilience may ironically imperil the chances of a positive determination of credibility.

Even when applicants are able and willing to describe the hardships they face, cross-cultural differences in the language they use to describe those hardships may inhibit their case. Jeff Chase, who after his time as an immigration attorney became an immigration judge, described this phenomenon to me clearly:

It's really important for the asylum seeker to realize that things that are commonly understood by them-that they might not feel they need to explain when talking to a member of their own family or a neighbor-when they talk to the credible fear asylum officer or immigration judge, [they] have to act like this person doesn't know anything about where I come and how things operate there. So, if they're going to say that, for example, their domestic partner was abusive to them or the gang was extorting money from them, they should really make sure to paint the full picture of how things operate there. 
This problem is not unique to the United States; Maryns (2017) highlights how language itself holds meaning that might be locally bound rather than interculturally transferable. Her work shows how Belgium asylum interviews privilege common and local uses of English over international variants of the language in ways that fail to meet the communicative needs of incoming asylum seekers as they narrate their pasts. Uprooting the normalcy of some culturallybound terms, Judge Chase suggests, can help to address this problem and bolster one's case; however, for the reasons the narrators in this project have already described, painting a "full picture" as he recommends is difficult. Lived experiences that seem implausible within an immigration judge's cultural framework may be particularly difficult for asylum seekers to prove, even if those experiences are commonplace and unremarkable in the asylum seeker's former social context. This reality confirms and underscores Smith-Khan's (2017) assertion that asylum narratives are not authored by asylum seekers alone; they are co-constructed by the interviewing officer who both directs the conversations and overlays their own cultural understanding onto the applicants' words. Considering that Smith-Khan's perspective is from the Australian asylum process, Maryns' is from Belgium, and Judge Chase's reflections are about the U.S. asylum system, makes clear that this communicative challenge is endemic to international asylum processes that span continents rather than specific to one particular national context.

Moreover, an asylum applicant and an agent of the government may operate on differing definitions for words that describe social realities. The burden to ensure clear interpretation of such words falls to the asylum seeker, who may be unaware that a discrepancy even exists. Judge Chase offered an illustrative example: "Someone coming from a small-town American viewpoint hears the word 'gang,' and they might think of some teenagers that hang out on a corner that bother people walking by." Many cases he heard during his time on the bench involved highly organized and dangerous groups such as MS-13 and Mara 18 that act, he explained, "as de facto governments in the areas that they live. They're controlling basically armies where they're having billions of dollars in cash flow from drug sales and extortion, where their reach is international, where they're carrying out functions that would normally be associated with governments." In the case of attempting to find relief from persecution of a gang that matches this description, an asylum seeker would need not only to recognize a likely difference in the way gangs are defined in these contexts, but also clearly and convincingly demonstrate the gang's scope and threat.

Much as government recommendations for dealing with asylum seekers from different backgrounds may seek to standardize interactions between asylum officers or immigration judges and asylum seekers, it is down to the individual governmental representative to reach their own conclusions about credibility and deservingness. One metric for the randomness with which these assessments are made is the wide disparity in outcomes from one immigration court - or one immigration judge - to another. From fiscal years 2014 to 2019, of the five immigration courts that handled almost 50\% of asylum cases, denial rates ranged from 26\% (New York) to almost $92 \%$ (Houston). Over that same period, two immigration judges denied $100 \%$ of the cases they ruled on, while ten others denied fewer than 10\% (TRAC Reports, 2020).

Because every case hinges on immigration judges' interpretation of applicants' narratives of their experiences and the relationship of those experiences to immigration law, the U.S. State Department provides country condition reports for use by officers and judges trying to paint the bigger picture of life in any given country (U.S. Department of State, 2019). While the State Department assures users that these reports are diligently researched and their contents approved by a number of area experts, Amnesty International (Demant, 2018) has charged that the reports in recent years have in fact been altered by a "unprecedented and alarming level of politicized editing by the Trump administration that undermines the credibility of the reports." Likewise, Human 
Rights Watch (Gramer, 2018) accused the 2017 reports of containing "massive omissions" that threaten to undermine the perceived credibility of asylum applicants. Of course, even the most well-intentioned and thoroughly researched country condition reports cannot account for the experiences of every citizen; applicants whose experiences of persecution fall outside the norm for a given country may have an even more difficult time proving their case (see Akin, 2017).

Sometimes even mundane and barely perceptible differences in culturally-bound ways of describing a memory directly affect a case. These differences are supported by research in cognitive neuroscience; everything from the age of a person's earliest memory to the emphasis a memory puts on the self or the community to the specificity and detailedness of autobiographical memories has been shown to vary from culture to culture (Nelson, 2010; Wang, 2001, 2016). Elizabeta pointed out that even something as banal as differences in the way distances are measured from one culture to the next can cause misunderstandings in an asylum case. She remembers that in the first asylum case she ever represented, there was a "misunderstanding of distance based on the fact that that individual is from a country who uses the metric system," she remembers. Although such a difference seems minor compared to the earlier illustrations in this section, Elizabeta pointed out that because officers and judges are trained to look for even minor discrepancies in narratives as signals of the possibility of fraud, even a small culturally-rooted misunderstanding might have a big impact. "There are so many little things that could be a critical fact that if you don't have [an] advocate next to you, [who is] taking notes, monitoring, making sure, going through the testimony, going through the facts, aligning all those things," she told me. Cultural norms big and small permeate asylum cases in ways both visible and invisible.

\section{Conclusions}

Asylum is in a state of crisis, underlining the need for a better understanding of how asylum seekers' communication styles, narrative ability, and culturally-bound behaviors during their legal process may advance or threaten the potential for a successful outcome. The problems that result from the presence of differing cultural norms in the asylum process have no easy solution. These pressures mounted as the former Trump administration used the COVID-19 pandemic as a lever to instate even stricter asylum policies, summarily turning arrivals at the southern border back to Mexico while continuing to hold asylum seekers in detention centers - congregate settings in which the risk of spreading the virus is highest.

Even in the midst of the current dire climate, there are many attorneys, asylum psychologists, immigration officers, and judges who believe in the universal human right to seek asylum and have demonstrated creative adaptability and compassion toward asylum seekers. In her experiences accompanying clients to court to provide psychological evaluations, Dr. AkinsulureSmith recalls instances where judges recognized how difficult verbal testimony would likely be in a particular case, and chose mercifully not to require the applicant to recount the graphic details in the courtroom. She told me, 'I've been with people who've had really empathetic judges who've said, 'You know what? I've read the affidavit. I read this woman's statement, she went through all these rapes. We don't need to go through the details, let's just move along." Sparing the applicant from retelling the painful details of her story after she had already recounted it multiple times for her attorney and the pro-bono psychiatrist attending her case, this judge chose to prioritize her written testimony instead, demonstrating one means through which judges may sometimes be able to make use of different mediums of communication to mitigate the trauma of the asylum process.

The current U.S. political climate weighs heavily on those working in support of the human rights of asylum seekers. Martha retired from her post as an asylum officer one year after Donald Trump took office as President. "I'd still be there if we had a different administration," she told 
me. "It just got too much. I can't deal with him, separating families and throwing children in the cages. ... I just felt beaten down by it. I think what the current administration is doing to these people is criminal." Judge Chase retired in May 2017, and regularly speaks with other judges who are still on the bench. He shared that some have told him, "You have no idea how bad things are. You can't even imagine. Whatever you can imagine, it's 100 times worse." The year he retired, Judge Chase founded The Roundtable of Former Immigration Judges, a group that has been outspoken about the harmful effects of the unprecedented attacks against the right to seek asylum the Trump administration has made, including limiting the types of claims eligible for asylum and requiring judges to process cases in less time than is necessary to give fair consideration to a case. Newly-retired judges regularly reach out to Chase's group wanting to join. "The second they retire, I get to hear from them, and so many of them just come out so angry," he explained. In an article reporting on the unusual number of immigration judges who retired early under Trump, Aleaziz (2019) details the policy changes that have undermined judges' prior sense of authority to fairly judge asylum cases; many now feel like "cogs in a deportation machine, as opposed to neutral arbiters given time to thoughtfully analyze the merits of each case," Aleaziz reports. When the individuals who are determined to uphold the universal right to asylum are driven from the job by policies they feel they cannot ethically uphold, more room opens up for governmental asylum personnel who do not question the threat to human rights the current system invites.

In this work, I have shown how the parameters required by the asylum application and interview/hearing process do not account for culturally specific ways of remembering and storytelling, and how discrepancies in definitions and the cultural normalization and internalization of persecution leads asylum applicants to communicate in ways that may threaten their cases. Asylum seekers must navigate a series of perpetual communicative double binds. The stylistic and rhetorical confines of the communicate interactions that stand between an applicant and protection from persecution leaves applicants at a remarkable disadvantage from the start; the current legal system exacerbates rather than mitigates these communicative challenges. Applicants are required to conform to descriptive and persuasive narrative conventions, and the goalposts move every time they have to communicate with a new individual agent of the US government. The extent to which this is true can only be determined by listening to those who have endured it. The narrators in this project illuminate the unique and unnerving result of the interaction of trauma with the communicative tenets of the U.S. asylum process. By drawing to the fore insights of the individuals who have been in the room when asylum decisions are rendered, this project suggests that the United States' responsibility to process asylum seekers ethically and fairly requires greater attention to the role that communication and culture play in the search for legal protection.

\section{Acknowledgements}

This project was supported by fellowships from the Columbia University Institute for the Study of Human Rights and the Advanced Research Collaborative at the CUNY Graduate Center. Funding from The Waterhouse Family Institute for the Study of Communication and Society at Villanova University and the Dean's Office of the Weissman School of Arts and Sciences at Baruch College made the project possible. Special thanks to my fantastic research assistants Nora Lambrecht and Valentina Floegel. 


\section{References}

Acevedo, M. J. (2008). Battered immigrant Mexican women's perspectives regarding abuse and help-seeking. Journal of Multicultural Social Work, 8(3-4), 243-282. https://doi.org/10.1300/J285v08n03_04

Akin, D. (2017). Queer asylum seekers: translating sexuality in Norway. Journal of Ethnic \& Migration Studies, 43(3), 458-474. https://doi.org/10.1080/1369183X.2016.1243050

Aleaziz, H. (2019, February 13). Being an immigration judge was their dream. Under Trump, it became untenable. Buzzfeed News. https://www.buzzfeednews.com/article/hamedaleaziz/immigration-policy-judge-resigntrump

American Bar Association. (2018). About notario fraud. https://www.americanbar.org/groups/public_interest/immigration/projects_initiatives/figh t-notario-fraud/about_notario_fraud/

American Immigration Council. (2016). Access to council in immigration court. https://www.americanimmigrationcouncil.org/research/access-counsel-immigration-court

American Immigration Council. (2018). Asylum in the United States. https://www.americanimmigrationcouncil.org/sites/default/files/research/asylum_in_the_ united_states.pdf

American Immigration Lawyers Association. (2019, December 23). Call for examples: USCIS rejection of Forms I-589 due to claimed incompleteness. https://www.aila.org/advomedia/agency-liaison/case-examples/uscis-rejection-forms-i-589-claimed-incompleteness

Ardalan, S. (2015). Access to justice for asylum seekers: Developing an effective model of holistic asylum representation. University of Michigan Journal of Law Reform, 48(4), 1001-1038.

Bellevue/NYU Program for Survivors of Torture. (2019). Client demographics. https://www.survivorsoftorture.org/

Bhabha, J., \& Smith, J. (2007). Independent children, inconsistent adults: Child migration and the legal framework. https://www.unicef-irc.org/publications/503-independent-childreninconsistent-adults-international-child-migration-and-the-legal.html

Blommaert, J. (2001). Investigating narrative inequality: African asylum seekers' stories in Belgium. Discourse \& Society, 12(4), 413-449. https://doi.org/10.1177/0957926501012004002

Bohmer, C., \& Shuman, A. (2007). Producing epistemologies of ignorance in the political asylum application process. Identities: Global Studies in Cultural Power, 14(5), 603-629.

Bond, C. F. Jr., \& Atoum, A. O. (2000). International deception. Personality and Social Psychology Bulletin, 26(3), 385-395.

Bremner, J. D., \& Marmar, C. R. (Eds.). (1998). Trauma, memory, and dissociation. American Psychiatric Press.

Carrillo, H. (2010). Immigration and LGBT rights in the USA: Ironies and constraints in US asylum cases. In Routledge handbook of sexuality, health and rights (pp. 466-474). Routledge.

Chase, J. S. (2017, June 29). Making your trial record: The importance of dates. https://www.jeffreyschase.com/blog/2017/6/29/making-your-trial-record-the-importanceof-dates

Coundouriotis, E. (2006). The dignity of the "unfittest": Victims' stories in South Africa. Human Rights Quarterly, 28(4), 842-867.

Crespo, M., \& Fernández-Lansac, V. (2016). Memory and narrative of traumatic events: A literature review. Psychological Trauma: Theory, Research, Practice, \& Policy, 8(2), 14956. https://doi.org/10.1037/tra0000041 
Davis, C. (2019, December 23). Bureaucracy as a weapon: How the Trump administration is slowing asylum cases. The Guardian. https://www.theguardian.com/usnews/2019/dec/23/us-immigration-trump-asylum-seekers

Dekel, S., \& Bonanno, G. A. (2013). Changes in trauma memory and patterns of posttraumatic stress. Psychological Trauma: Theory, Research, Practice, \& Policy, 5(1), 26-34.

Demant, T. (2018). A critique of the US Department of State 2017 country reports on human rights practices. https://medium.com/@amnestyusa/a-critique-of-the-us-department-of-state2017-country-reports-on-human-rights-practices-f313ec5fe8ca

"Deported to Danger: United States deportation policies expose Salvadorans to death and abuse." (2020). Human Rights Watch. https://www.hrw.org/report/2020/02/05/deporteddanger/united-states-deportation-policies-expose-salvadorans-death-and

Dolnick, S. (2011, July 12). Immigrants may be fed false stories to bolster asylum pleas. New York Times. http://www.nytimes.com/2011/07/12/nyregion/immigrants-may-be-fed- falsestories-to-bolster-asylum-pleas.html

Engelhard, I. M., van den Hout, M. A., \& McNally, R. J. (2008). Memory consistency for traumatic events in Dutch soldiers deployed to Iraq. Memory, 16, 3-9.

Fisher, W. (1989). Human communication as narration: Toward a philosophy of reason, value, and action. University of South Carolina Press.

Fobear, K. (2015). "I thought we had no rights": Challenges in listening, storytelling, and representation of LGBT refugees. Studies in Social Justice, 9(1). https://doi.org/10.26522/ssj.v9i1.1137

Gibb, R., \& Good, A. (2014). Interpretation, translation and intercultural communication in refugee status determination procedures in the UK and France. Language \& Intercultural Communication, 14(3), 385-399. https://doi.org/10.1080/14708477.2014.918314

Giosan, C., Malta, L., Jayasinghe, N., Spielman, L., and Difede, J. (2009). Relationships between memory inconsistency for traumatic events following 9/11 and PTSD in disaster restoration workers. Journal of Anxiety Disorders. 23, 557-561.

Graham, B., Herlihy, J., \& Brewin, C. R. (2014). Overgeneral memory in asylum seekers and refugees. Journal of behavior therapy \& experimental psychiatry, 45(3), 375-380.

Gramer, R. (2018, April 21). Human rights groups bristling at State Department report: What's not in the report is as important as what's in it. Foreign Policy. https://foreignpolicy.com/2018/04/21/human-rights-groups-bristling-at-state-humanrights-report/

Gramlich, J. (2020, March 2). How border apprehensions, ICE arrests and deportations have changed under Trump. Pew Research Center Fact Tank. https://www.pewresearch.org/facttank/2020/03/02/how-border-apprehensions-ice-arrests-and-deportations-have-changedunder-trump/

Gurer, C. (2019). Refugee Perspectives on Integration in Germany. American Journal of Qualitative Research, 3(2), 52-70. https://doi.org/10.29333/ajqr/6433

Haas, B. M. (2017). Citizens-in-Waiting, Deportees-in-Waiting: Power, temporality, and suffering in the US asylum system. Ethos, 45 (1), 75-97.

Hackett, C., \& Rolston, B. (2009). The burden of memory: Victims, storytelling and resistance in Northern Ireland. Memory Studies, 2(3), 355-376. https://doi.org/10.1177/1750698008337560

Hellawell, S. J., \& Brewin, C. R. (2004). A comparison of flashbacks and ordinary autobiographical memories of trauma: Content and language. Behavior Research \& Therapy, 42, 1-12.

Heller, P. (2009). Challenges facing LGBT asylum-seekers: The role of social work in correcting 
oppressive immigration processes. Journal of Gay \& Lesbian Social Services, 21(2-3), 294-308. https://doi.org/10.1080/10538720902772246

Herlihy, J., \& Turner, S. (2007). Asylum claims and memory of trauma: Sharing our knowledge. British Journal of Psychiatry, 191(1), 3-4. https://doi.org/10.1192/bjp.bp.106.034439

Hlavka, H. R. (2014). Normalizing sexual violence: Young women account for harassment and abuse. Gender \& Society, 28(3), 337-358. https://doi.org/10.1177/0891243214526468

Jacquemet, M. (2015). Asylum and superdiversity: The search for denotational accuracy during asylum hearings. Language \& Communication, 44, 72-81.

Johnsen, G. E., \& Asbjørnsen, A. E. (2009). Verbal learning and memory impairments in posttraumatic stress disorder: The role of encoding strategies. Psychiatry Research, 165(12), 68-77. https://doi.org/10.1016/j.psychres.2008.01.001

Kälin, W. (1986). Troubled communication: Cross-cultural misunderstandings in the asylumhearing. The International Migration Review, 20(2), 230-241. https://doi.org/10.2307/2546033

Langballe, A., \& Schultz, J.- H. (2017). "I couldn't tell such things to others": Trauma-exposed youth and the investigative interview. Police Practice \& Research, 18(1), 62-74. https://doi.org/10.1080/15614263.2016.1229185

Maryns, K. (2013). Disclosure and (re)performance of gender-based evidence in an interpretermediated asylum interview. Journal of Sociolinguistics, 17(5), 661-686. https://doi.org/10.1111/josl.12056

Maryns, K. (2017). The use of English as ad hoc institutional standard in the Belgian asylum interview. Applied Linguistics, 38(5), 737-758.

McAdams, D. P. (2001). The psychology of life stories. Review of General Psychology, 5(2), 100122. https://doi.org/10.1037/1089-2680.5.2.100

McFadyen, G. (2019). Memory, language and silence: Barriers to refuge within the British asylum system. Journal of Immigrant \& Refugee Studies, 17(2), 168-184.

Millbank, J. (2010). From discretion to disbelief: Recent trends in refugee determinations on the basis of sexual orientation in Australia and the United Kingdom. The International Journal of Human Rights, 13(2-3), 391-414. https://doi.org/10.1080/13642980902758218

Mossad, N. (2019). Annual Flow Report, Refugees and Asylees: 2018. U.S. Department of Homeland Security Office of Immigration Statistics. https://www.dhs.gov/sites/default/files/publications/immigrationstatistics/yearbook/2018/refugees_asylees_2018.pdf

Nelson, K. (2010). Self and social functions: Individual autobiographical memory and collective narrative. Memory, (11)2, 125-136. https://doi.org/10.1080/741938203

Phifer, D. (2019, March 29). Donald Trump calls asylum claims a 'big fat con job,' says Mexico should stop migrant caravans from traveling to U.S. border. Newsweek. https://www.newsweek.com/donald-trump-calls-asylum-claims-big-fat-con-job-saysmexico-should-stop-1379453

Rasoulpour, A. (2020, January 17). Writing your asylum story [presentation]. www.rifnyc.org/s/Asylum-Story_English.pdf

Ratini, T. (2019). Refugee. American Journal of Qualitative Research, 3(2), 97-99. https://doi.org/10.29333/ajqr/6432

SAMHSA. (2014). SAMHSA's concept of trauma and guidance for a trauma-informed approach. https://store.samhsa.gov/sites/default/files/d7/priv/sma14-4884.pdf

Samuelson, K. W. (2011). Post-traumatic stress disorder and declarative memory functioning: A review. Dialogues in Clinical Neuroscience, 13(3), 346-351.

Sharf, B. F., \& Vanderford, M. L. (2003). Illness narratives and the social construction of health. 
In T. L. Thompson, A. M. Dorsey, K. I. Miller, \& R. Parrott (Eds.), Handbook of health communication (pp. 9-34). Lawrence Erlbaum Associates.

Shuman, A., \& Bohmer, C. (2004). Representing trauma: Political asylum narrative. The Journal of American Folklore, 117(466), 394-414.

Smith-Khan, L. (2017). Negotiating narratives, accessing asylum: Evaluating language policy as multi-level practice, beliefs and management, Multilingua, 36(1), 31-57. https://doi.org/10.1515/multi-2015-0072

Smith-Khan, L. (2018). Contesting credibility in Australian refugee visa decision making and public discourse [Unpublished doctoral dissertation]. Macquarie University.

Smith-Khan, L. (2020). Migration practitioners' roles in communicating credible refugee claims. Alternative Law Journal, 45(2), 119-124. https://doi.org/10.1177/1037969X19884205

Spotti, M. (2018). "It's all about naming things right": The paradox of web truths in the Belgian asylum-seeking procedure. In N. Gill \& A. Good (Eds.), Asylum determination in Europe: Ethnographic perspectives (pp. 69-90). Palgrave MacMillan. https://doi.org/10.1007/9783-319-94749-5

Strange, D., \& Takarangi, M. K. (2015). Memory distortion for traumatic events: The role of mental imagery. Frontiers in Psychiatry 6(27). https://doi.org/10.3389/fpsyt.2015.00027

Stuhlmiller, C. (2001) The emotional nature of qualitative research. Narrative methods in qualitative research: potential for therapeutic transformation. In Gilbert, K. (Ed.), The emotional nature of qualitative research (pp. 63-80). CRC Press. https://doi.org/10.1201/9781420039283.

TRAC Reports. (2020). Asylum decisions vary widely across judges and courts - Latest results. https://trac.syr.edu/immigration/reports/590/

U.S. Citizenship and Immigration Services. (2012). USCIS asylum program: Information guide for prospective asylum applicants. https://www.uscis.gov/sites/default/files/USCIS/Humanitarian/Refugees\%20\%26\%20Asy lum/Asylum/Information\%20Guides\%20For\%20Prospective\%20Applicants/info-guidefor-prospective-asylum-applicants-english.pdf

U.S. Citizenship and Immigration Services. (2015). Types of asylum decisions. https://www.uscis.gov/humanitarian/refugees-and-asylum/asylum/types-of-asylumdecisions

U.S. Citizenship and Immigration Services. (2019a). Cross-cultural communication and other factors that may impede communication at an interview. https://www.uscis.gov/sites/default/files/document/foia/CrossCultural_Communication_L P_RAIO.pdf

U.S. Citizenship and Immigration Services. (2019b). I-589, Application for asylum and for withholding of removal, 09/10/19 edition. https://www.uscis.gov/i-589

U.S. Citizenship and Immigration Services. (2020). Obtaining asylum in the United States. https://www.uscis.gov/humanitarian/refugees-and-asylum/asylum/obtaining-asylum-inthe-united-states

U.S. Department of State. (2019). 2018 country reports on human rights practices. https://www.state.gov/reports/2018-country-reports-on-human-rights-practices/

Wang, Q. (2001). Culture effects on adults' earliest childhood recollection and self-description: Implications for the relation between memory and the self. Journal of Personality \& Social Psychology, 81(2), 220-233. https://doi.org/10.1037/0022-3514.81.2.220

Wang, Q. (2016). Remembering the self in cultural contexts: A cultural dynamic theory of autobiographical memory. Memory Studies, 9(3), 295-304. 
https://doi.org/10.1177/1750698016645238

Watson, J., \& Lee, M. (2020, October 1). Trump plans to slash refugee admissions to US to record low. U.S. News \& World Report. https://www.usnews.com/news/us/articles/2020-0930/trump-set-to-miss-required-deadline-for-2021-refugee-quota

Wernesjö, U. (2019). Across the threshold: Negotiations of deservingness among unaccompanied young refugees in Sweden. Journal of Ethnic \& Migration Studies. https://doi.org/10.1080/1369183X.201.

Wood, J. T. (2001). The normalization of violence in heterosexual romantic relationships: Women's narratives of love and violence. Journal of Social \& Personal Relationships, 18(2), 239-261. https://doi.org/10.1177/0265407501182005

Wooley, A. (2017). Narrating the "asylum story": Between literary and legal storytelling. International Journal of Postcolonial Studies, 19(3), 376-394. https://doi.org/10.1080/1369801X.2016.123158

Wyshak, G. (2009). The relation between change in reports of traumatic events and symptoms of psychiatric distress. General Hospital Psychiatry, 16(4), 290-297. https://doi.org/10.1016/0163-8343(94)90009-4

\section{Notes on Contributors}

Sarah C. Bishop is an Associate Professor at Baruch College, City University of New York and serves on the Board of Directors of the immigrant-serving nonprofit Mixteca Organization. She is the author of Undocumented Storytellers: Narrating the Immigrant Rights Movement (Oxford University Press, 2019; winner of the Best Book Award, American Studies Division of the National Communication Association), and U.S. Media and Migration: Refugee Oral Histories (Routledge, 2016; winner of the Sue DeWine Distinguished Scholarly Book Award). 